\title{
DEHALOGENATION OF CHLOROBROMOPHENOL BY OZONATION USING HETEROGENEOUS CATALYST
}

\author{
NDABANKULU V.O. \\ MADDILA S. \\ JONNALAGADDA S.B.*
}

Received: $16 / 12 / 2015$

Accepted: 29/02/2016

Available online: $14 / 04 / 2016$

\author{
School of Chemistry, University of KwaZulu-Natal \\ Westville campus, Chiltern Hills, Durban-4000, South Africa
}

\section{ABSTRACT}

Ozone initiated oxidation of 2-chloro,4-bromophenol, (CBP) in aqueous system catalyzed by 1, 2.5 and 5\% loadings of 1:1 molar ratio of $\mathrm{Ce}-\mathrm{Zr}$ oxide on $\mathrm{TiO}_{2}$ were studied. The synthesized catalysts were characterized via BET, ICP, PXRD, TPD, TEM, SEM, and FT-IR analysis. The powder XRD data revealed that Ce-Zr exists in three different phases on titania. SEM and SEM-EDX confirmed well dispersed metal oxides on titania surface. ${ }^{1} \mathrm{H} N M R, \mathrm{R}$ and GC-MS positively confirm hydroxyfumaric acid (HFA) and oxalic acid $(\mathrm{OA})$ as reaction products. $5 \% \mathrm{Ce}-\mathrm{Zr} / \mathrm{TiO}_{2}$ showed best performance with $100 \%$ conversion in $4 \mathrm{~h}$.

Key words: Chlorobromophenol; Ozonation; Ceria/Zirconia, $\mathrm{TiO}_{2} ;$ Hydroxyfumaric acid; Oxalic acid.

\section{Introduction}

Halogenated organics are broadly used in various sectors of industry and in agriculture. Halophenols (chloro, bromo) are widely used as wood preservatives and they are also used in the synthesis of chemicals as industrial intermediates, insecticides, lubricants and dyes (Zhanga et al., 2009; Slack et al., 2005; Richardson and Ternes, 2014). They are considered risky pollutants as they are non-biodegradable, bioaccumulates, toxic, mutagenic and carcinogenic (Verschueren, 1983; Tamer et al., 2006; Maddila et al., 2014). Additionally, the halophenols are non-biodegradable in nature, after being released into environments they endure for long periods and then prone to accumulate in organic tissues [Maddila et al., 2013a, 2013b]. There appears the demand for efficient methods for removal of chloro, bromo functional groups in the organics from the industrial discharges which contaminate the ground water (Maddila et al., 2013; 2016a; 2016b). This has aroused interest in the dehalogenation of halophenols present in industrial effluents.

Ozonation is excellent method in treating wastewaters encompassed organics and is extensively used globally in the water treatment including for the effective microbial disinfection (Tamer et al., 2006; Jonnalagadda et al., 2012). Nowadays, ozone consumption has expressively increased in treatment of water comprising various organic or inorganic compounds (Maddila et al., 2013a; 2016a; 2016b). The oxidation potential of ozone is higher than the chlorine compounds. Oxidation potential is the strength its reactions with refractory pollutants. Molecular ozone is not only a powerful oxidant but also selective in reactions with specific nucleophilic molecules, but its reaction with some organic compounds occurs in a slow manner. Ozone is unstable in aqueous medium and under basic $\mathrm{pH}$ conditions decomposes to hydroxyl radicals ('OH) (Maddila et al., 2015a; 2015b). Compared to molecular ozone, ${ }^{\circ} \mathrm{OH}$ is much reactive and can attack variety of organic molecules, but with less selectivity (Kasprzyk-Hordern et al., 2003), which formed from ozone decomposition and reacts non-specifically with most of the substances (Chetty et al.,

Ndabankulu V.O., Maddila S. and Jonnalagadda S.B. (2016), Dehalogenation of chlorobromophenol by ozonation using heterogeneous catalyst, Global NEST Journal, 18(2), 242-250. 
2012). $\mathrm{O}_{3}$ forms $\mathrm{OH}$ via decomposition reactions of $-\mathrm{OH}$ ions and/or dissociated hydrogen peroxide $\left(\mathrm{H}_{2} \mathrm{O}_{2}\right)$. The $\mathrm{H}_{2} \mathrm{O}_{2}$ formation in the process of ozonation of different organic compounds was detected (Maddila et al., 2013a; 2013b). The 'radical chain reactions' leading to 'OH generation are established with the involvement of various intermediate radical species (Kasprzyk-Hordern et al., 2003; Jonnalagadda et al., 2012). In the process of ozonation of the industrial wastewater [Maddila et al., 2016a, 2016b], the establishment of radical chain with $-\mathrm{OH}$ ions and its expansion with $\mathrm{H}+$ and change in reaction $\mathrm{pH}$ is not enough to increase the $\mathrm{OH}$ concentrations. In the advanced oxidation processes (AOPs) for treatment of industrial wastewaters, the use of ozone and heterogeneous catalysts has considerably increased (Jonnalagadda et al., 2012). The heterogeneous catalysts are widely used as they show good stability, negligible losses and improve the efficacy of ozone decomposition (Maddila et al., 2013a). These catalyst materials can also be easily recovered and reused. The efficacy of the catalytic ozonation process depends mainly on the surface properties of the catalyst and the $\mathrm{pH}$ of the solution (Kasprzyk-Hordern et al., 2003). The metals, metal oxides and metal oxides with or without support are the heterogonous catalysts used predominantly. The use of $\mathrm{Ce}$ based catalyst is has shown to improve the formation of hydroxyl radicals which play a key role in the mineralization of CBP and other organic pollutants (Maddila et al., 2013a; 2014). The catalysts with more than one metal generally exhibit synergistic behavior, which makes these catalysts more efficient.

The main aim of the research was to explore the effect of Ce- $\mathrm{Zr}$ loaded on titania as heterogeneous catalysts for degradation of chlorobromophenol with ozone as an oxidant in aqueous solutions. In addition to comparing the activity of the loading of the catalyst on titania, a detailed analysis of the product profile and $\%$ conversion of the substrate was also carried out under varied conditions.

\section{Materials and methods}

\subsection{Catalyst preparation}

The synthesis of the metal oxide supported catalysts was done by wet impregnation method. Briefly, desired amount of cerium nitrate, zirconium nitrate were dissolved in double distilled water $(20 \mathrm{ml})$. Into the $20 \mathrm{~mL}$ solution was added Titania $(5.0 \mathrm{~g})$ and stirred initially for $3 \mathrm{~h}$ at room temperature and thereafter for overnight. The as-prepared catalysts were dried at in an oven for $12 \mathrm{~h}$ at $110-130{ }^{\circ} \mathrm{C}$ and then calcined in air at $450{ }^{\circ} \mathrm{C}$ for $3 \mathrm{~h}$ the $1.0 \%, 2.5 \%$, and $5.0 \% \mathrm{w} / \mathrm{w}$ of $\mathrm{Ce}-\mathrm{Zr} / \mathrm{TiO}{ }_{2}$ catalysts (KasprzykHordern et al., 2003; Maddila et al., 2014; Chetty et al., 2012).

\subsection{Ozonalysis experiment}

For ozone generation, a Fischer Ozone 500 generator was used. Ozone enriched oxygen stream was passed through a sintered glass (porosity 2) into the $50 \mathrm{~cm}^{3}$ reactor at a flow rate of $10 \mathrm{ml}$ per min. The reactor temperature was maintained at $19 \pm 1^{\circ} \mathrm{C}$ by circulating water through double walled jacket. For each run $20 \mathrm{ml} 10 \% \mathrm{w} / \mathrm{v}$ of 2-chloro,4-bromophenol (CBP) and fixed ozone concentration ( $0.05 \mathrm{M})$ and flow rate of $10 \mathrm{ml} \mathrm{min}^{-1}$. The concentration of the pollutant used was a bit more than that is found in the wastewater systems. This was due to the fact that the instrument sensitivity and limit of detection had to be considered. I.e. for this work a double beam Shimadzu spectrometer was used to monitor the disappearance of CBP.

A magnetic stirrer was used to ensure continuous mixing. Ozone concentration in oxygen stream was determined using KI method (Kasprzyk-Hordern et al., 2003; Maddila et al., 2014). Before and after each of the experiment the flow rate and ozone content were monitored in duplicate runs. Experiments were done were done with $1,2.5$ and $5 \mathrm{wt} \%$ of $\mathrm{Ce}-\mathrm{Zr} / \mathrm{TiO}_{2}$. The $5 \mathrm{wt} \%$ showed better efficiency in degradation of $\mathrm{CBP}$ and as a results it was used in all different conditions that were tested. In each experiment 100 , 150,200 , and $250 \mathrm{mg} \mathrm{l}^{-1}$ catalyst was used. The results shown in the paper are for the optimum conditions which were $5 \mathrm{wt} \% \mathrm{Ce}-\mathrm{Zr} / \mathrm{TiO}_{2}$ (The deviation within the replicates was \pm 0.0005 ). replicates. 


\subsection{Instrumentation}

All the catalyst characterization and product identification was achieved adopting the following techniques: PXRD, SEM-EDX, TEM, $\mathrm{N}_{2}$ sorption, ICP, FTIR, ${ }^{1} \mathrm{H}$ NMR spectral analysis (Maddila et al., 2013; 2014; Oseghe et al., 2015) Products were analyzed using Perkin Elmer Clarus 400 Gas Chromatograph equipped with an El mode Mass spectra photometer, the GC-MS analysis was executed in El mode with 35-500 amu intervals. Furthermore, J \& W DB5MS column of specifications, length ( $30 \mathrm{~m}$ ), diameter (250 $\mu \mathrm{m})$ and film thickness $(0.25 \mu \mathrm{m})$ was used. Helium was used as a carrier gas, and the temperature ramp program used during the GC-MS analysis is as follows: $50{ }^{\circ} \mathrm{C}(2 \mathrm{~min}), 20^{\circ} \mathrm{C}$ min-1 until $300{ }^{\circ} \mathrm{C}(10 \mathrm{~min})$.

\section{Results and discussion}

\subsection{X-Ray diffraction}

X-ray diffractograms of bimetallic catalyst are presented in Figure 1. XRD diffractograms showed the presence of cerium oxide and zirconium oxide on the $\mathrm{TiO}_{2}$ support. The maximum intense and sharp peak at $2 \theta \approx 25^{\circ}$ corresponds to (101) plane of $\mathrm{TiO}_{2}$ (PDF-ICDD 21-1272). The peaks obtained at approximately $48^{\circ}, 55^{\circ}$ and $69^{\circ}$ corresponds to (220), (311) and (400) planes respectively and confirms the presence of pure $\mathrm{CeO}_{2}$ (PDF-ICDD 34-0394) phase. XRD patterns showed the presence of $\mathrm{ZrO}_{2}$ phase in the catalyst. Slight shift in peaks was observed due to variation in metal loadings on $\mathrm{TiO}_{2}$ support.

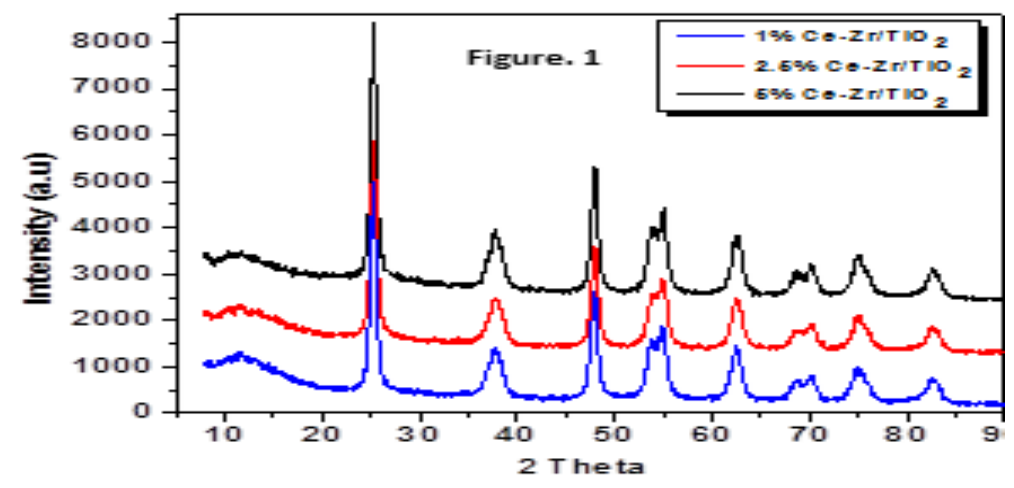

Figure 1. XRD spectra $1 \%, 2.5 \%$ \& $5 \% \mathrm{Ce}-\mathrm{Zr}$ loaded on $\mathrm{TiO}_{2}$ catalyst

\subsection{BET Surface and elemental analysis}

Surface area and pore volume of the prepared bimetallic catalysts are presented in Table 1. All three bimetallic catalysts show minor difference in both pore volume and surface area. It is clear from the table that, addition and dispersion of $\mathrm{Ce}$ and $\mathrm{Zr}$ in $\mathrm{TiO}_{2}$ support enhances the surface area of all catalyst. Mixture of ceria, zirconia and $\mathrm{TiO}_{2}$ enhances the surface area of $\mathrm{TiO}_{2}$ have been reported in the literature (Reddy et al., 2003). The study indicates that bimetallic catalysts show high surface area and low pore volume than $\mathrm{TiO}_{2}$ support without metal addition. Figure 2 shows the $\mathrm{N}_{2}$ sorption isotherm of the catalyst typical for type IV isotherms which therefore implies mesoporous materials. Table 1 also indicates the actual metal loadings of catalyst determined by ICP.

Table 1. BET surface area, elemental analysis and TPD data of Ce-Zr loaded supports

\begin{tabular}{|c|c|c|c|c|c|c|c|c|c|}
\hline \multirow[t]{2}{*}{ Catalyst } & \multicolumn{2}{|c|}{ ICP (mol\%) } & \multirow{2}{*}{$\begin{array}{c}\text { Surface } \\
\text { area } \\
\left(\mathrm{m}^{2} \mathrm{~g}^{-1}\right)\end{array}$} & \multirow{2}{*}{$\begin{array}{c}\text { Pore } \\
\text { volume } \\
\left(\mathrm{cm}^{3} \mathrm{~g}^{-1}\right)\end{array}$} & \multirow{2}{*}{$\begin{array}{c}\text { Pore } \\
\text { diameter (Å) }\end{array}$} & \multicolumn{2}{|c|}{ EDX } & \multirow{2}{*}{$\begin{array}{l}\text { Acidity } \\
(\mathrm{mmol} \\
\left.\mathrm{NH}_{3} \mathrm{~g}^{-1}\right)\end{array}$} & \multirow{2}{*}{$\begin{array}{l}\text { Specific } \\
\text { acidity } \\
\text { (mmol } \\
\mathrm{NH}_{3} \mathrm{~g}^{-1} \text { ) }\end{array}$} \\
\hline & $\mathrm{Ce}$ & $\mathrm{Zr}$ & & & & $\mathrm{Ce}$ & $\mathrm{Zr}$ & & \\
\hline $\mathrm{TiO}_{2}$ & - & - & 88 & 0.42 & 115 & - & - & 620 & 7.04 \\
\hline $1 \% \mathrm{Ce}-\mathrm{Zr} / \mathrm{TiO}_{2}$ & 0.44 & 0.48 & 124 & 0.33 & 108 & 0.37 & 0.41 & 541 & 4.39 \\
\hline $2.5 \% \mathrm{Ce}-\mathrm{Zr} / \mathrm{TiO}_{2}$ & 1.22 & 1.24 & 111 & 0.33 & 97 & 1.11 & 1.12 & 422 & 3.81 \\
\hline $5 \% \mathrm{Ce}-\mathrm{Zr} / \mathrm{TiO}_{2}$ & 2.47 & 2.45 & 114 & 0.32 & 94 & 2.46 & 2.44 & 363 & 3.11 \\
\hline
\end{tabular}




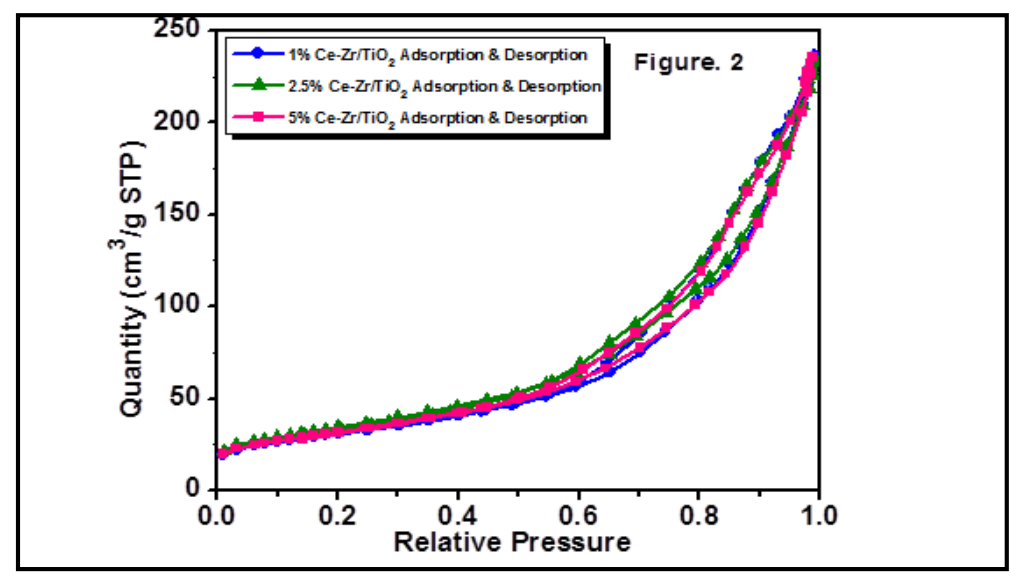

Figure 2. $\mathrm{N}_{2}$ Adsorption-Desorption Isotherms of catalysts

\subsection{SEM and TEM}

Figure $3(a, b, c)$ show SEM micrographs of bimetallic catalysts prepared with $1,2.5$ and $5 \mathrm{wt} \% \mathrm{Ce}-\mathrm{Zr}$ on $\mathrm{TiO}_{2}$ support. Figure $3(d, e, f)$ reveal that all catalysts having similar morphology and clusters of metal particles are present on the support surface. Cerium and zirconium metal particles were evenly dispersed on the surface of $\mathrm{TiO}_{2}$ support. It has been also observed that with the increase in metal loadings, the agglomeration of particles increases. Surface of the $\mathrm{TiO}_{2}$ support seems more covered with metals in the case of $5 \% \mathrm{Ce}-\mathrm{Zr} / \mathrm{TiO}_{2}$. Figure $3(\mathrm{~d}, \mathrm{e}, \mathrm{f})$ display the TEM images of $\mathrm{CeZr} / \mathrm{TiO}_{2}$ catalysts. An examination of the TEM images indicates that agglomeration of the catalyst. The TEM micrograph shows that particles are of less than $10 \mathrm{~nm}$ in size and randomly oriented with round, oval and elongated shaped metal oxide particles.

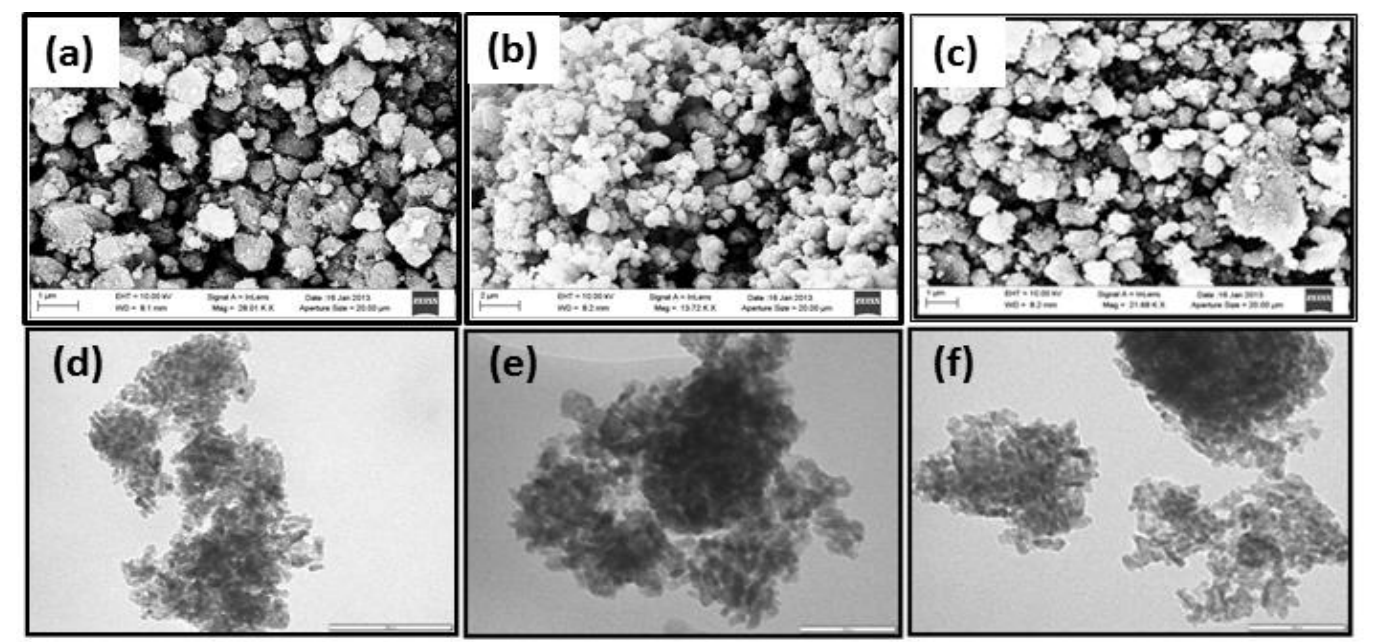

Figure 3. SEM images $(a, b, c)$ and TEM images $(d, e, e f)$ of $1 \%, 2.5 \%$ and $5 \% \mathrm{Ce}-\mathrm{Zr}$ on $\mathrm{TiO}_{2}$

\subsection{IR spectra}

The absorption bands observed at 788,796 and $790 \mathrm{~cm}^{-1}$ endorse the existence of $\mathrm{Ce}-\mathrm{Zr}$ on $\mathrm{TiO}_{2}$ (Figure 4). While $1 \%$ Ce-Zr on titania showed IR bands at $518 \mathrm{~cm}^{-1}$ and $1124 \mathrm{~cm}^{-1} ; 2.5 \% \mathrm{Ce}-\mathrm{Zr}$ displayed $542 \mathrm{~cm}^{-1}$ and $1057 \mathrm{~cm}^{-1}$ bands; plus the $5 \% \mathrm{Ce}-\mathrm{Zr}$ on titania exhibited bands at $548 \mathrm{~cm}^{-1}$ and $1053 \mathrm{~cm}^{-1}$. The peaks corresponding to Ce-Zr-O can be witnessed in all three samples as absorption bands at $1636 \mathrm{~cm}^{-1}$ and $1635 \mathrm{~cm}^{-1}$. The Ce-O vibrational stretching peaks for the three catalysts respectively can be observed at $425 \mathrm{~cm}^{-1}, 427 \mathrm{~cm}^{-1}$ and $434 \mathrm{~cm}^{-1}$. The absorption bands observed at $3213 \mathrm{~cm}^{-1}, 3258 \mathrm{~cm}^{-1}$ and $3255 \mathrm{~cm}^{-1}$ for $1 \%, 2.5 \%$ and $5 \% \mathrm{Ce}-\mathrm{Zr} / \mathrm{TiO}_{2}$ respectively confirm the manifestation of hydroxyl groups on their surfaces. 


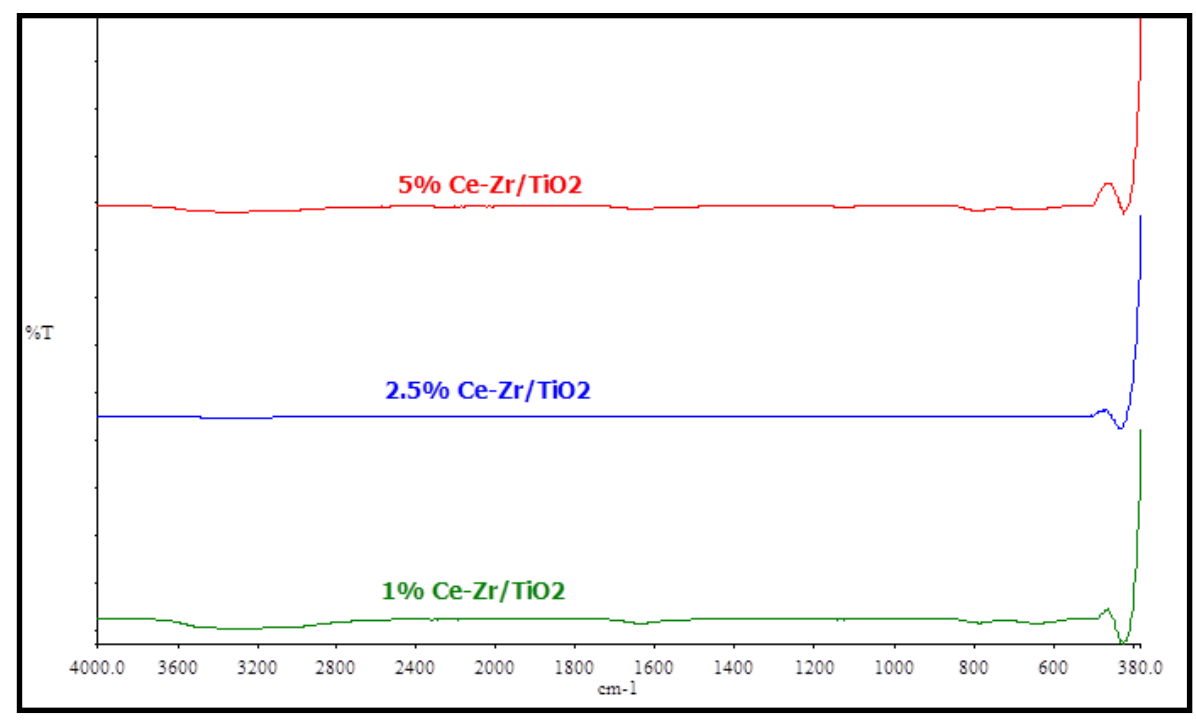

Figure 4. IR spectra of $1 \%, 2.5 \%$ and $5 \% \mathrm{Ce}-\mathrm{Zr}$ loaded on $\mathrm{TiO}_{2}$ supports

\subsection{Product characterisation}

During aeration of the samples with ozone enriched oxygen, the organic contents were extracted from the reaction mixture and analyzed at 60 min intervals in every reaction All samples were analyzed during the start of the reaction, i.e. $t=0$, but degradation of the pollutant was only observed after 60 min, therefore the results which are shown are only after degradation has started. Each run was carried out in triplicates and data obtained was with $\pm 2 \%$ error. Ozone concentration in oxygen stream was determined using KI method. After separation of the oxidation products from the parent compound (CBP) using column chromatography and the product mixture was characterised using GC-MS (Figure 5).

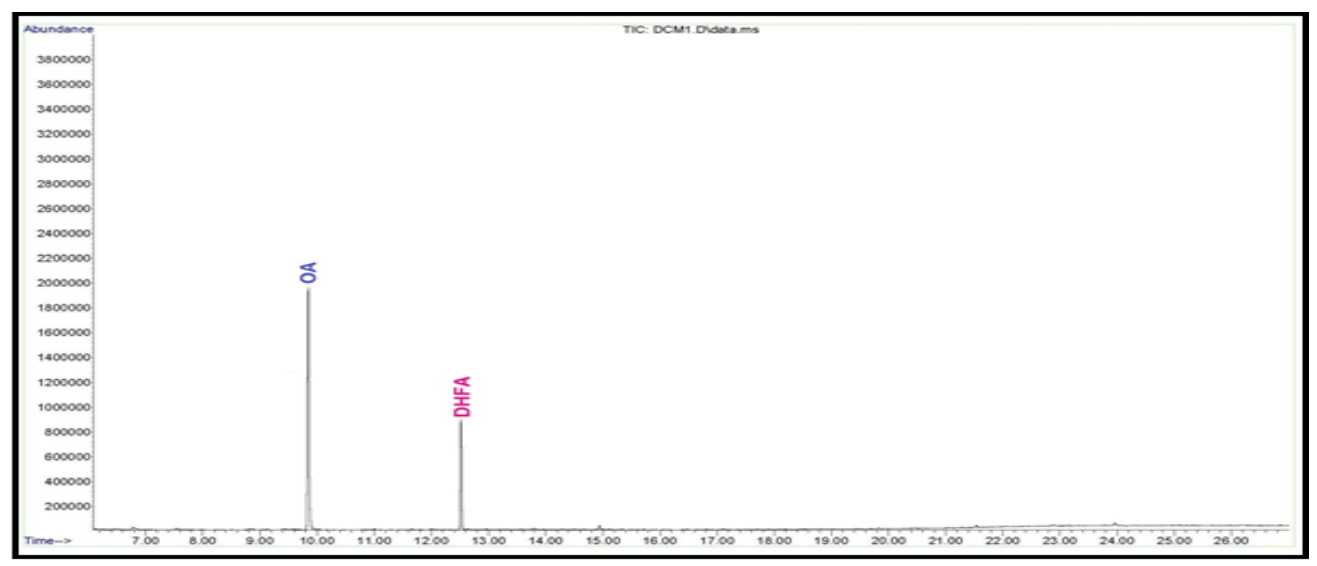

Figure 5. GC-MS chromatogram of product mixture

The mass spectra consequently confirmed the presence of two products namely hydroxyfumaric acid (HFA) and oxalic acid (OA). The proton NMR spectra of HFA displayed two singlets at $\delta 14.23 \mathrm{ppm}$ and $\delta$ $10.29 \mathrm{ppm}$ confirming the presence of $\mathrm{COOH}, \mathrm{CH}$ groups respectively (Figure 6.a). Infrared spectra of HFA revealed the representative absorption bands at $1629,3082,3320 \mathrm{~cm}^{-1}$ for the $\mathrm{C}=\mathrm{C} \mathrm{C}-\mathrm{H}$ and $\mathrm{COOH}$ stretching vibrations respectively (Figure 6.b). Further, the mass spectrum exhibited $\mathrm{m} / \mathrm{z}$ peak at 149 $(\mathrm{M}+\mathrm{H})$ (Figure 6c). Likewise, the oxidant product OA showed a broad singlet for $\mathrm{COOH}$ protons at $\delta 13.10$ ppm (Figure 7a). The absorption bands were obtained for the stretching frequencies of $\mathrm{COOH}, \mathrm{CH}$ and $\mathrm{C}=\mathrm{O}$ groups at 3444,3069 , and $1890 \mathrm{~cm}^{-1}$ respectively by the IR spectra of the OA product (Figure $7 \mathrm{~b}$ ). In addition, the mass spectrum indicated the $\mathrm{m} / \mathrm{z}$ peak at $91(\mathrm{M}+\mathrm{H})$ (Figure $7 \mathrm{c}$ ). The functional groups of oxidant products examined by IR and data of ${ }^{1} \mathrm{H}-\mathrm{NMR}$, mass spectra were consistent with one another. 
The partial mineralization of products and formation of $\mathrm{CO}_{2}$ during the ozonation process was positively verified by bubbling the gases through lime water, which turned milky. Ozone initiated oxidations are generally known to produce small chain biodegradable acids as the oxidation products Ozone was quantified using the KI method, where the lodometric titration was done using sodium thiosulfate and potassium lodate. This method was done so that the concentration of Ozone before and after the reaction.

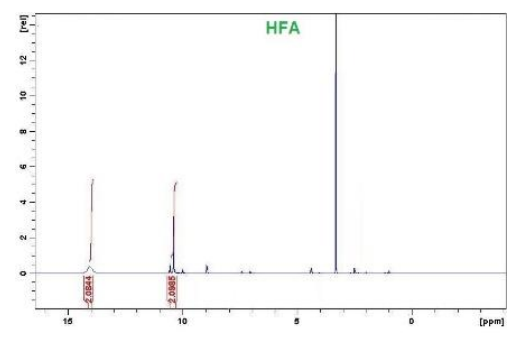

Figure 6a. ${ }^{1} \mathrm{H}$ NMR Spectra of HFA

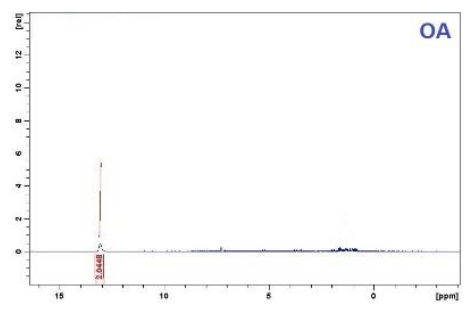

Figure 7a. ${ }^{1} \mathrm{H}$ NMR Spectra of $\mathrm{OA}$

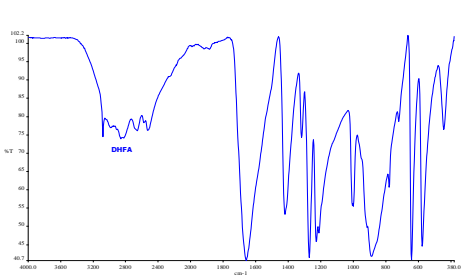

Figure 6b. Infrared Spectra of HFA

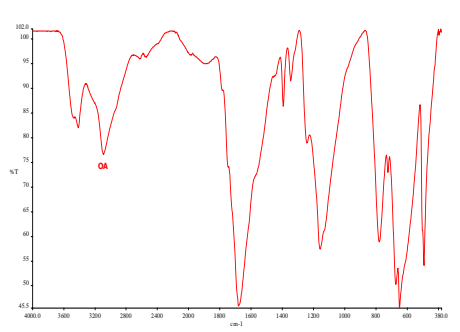

Figure 7b. Infrared Spectra of OA

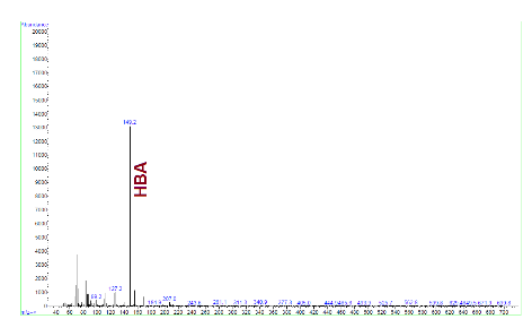

Figure 6c. Mass of HFA

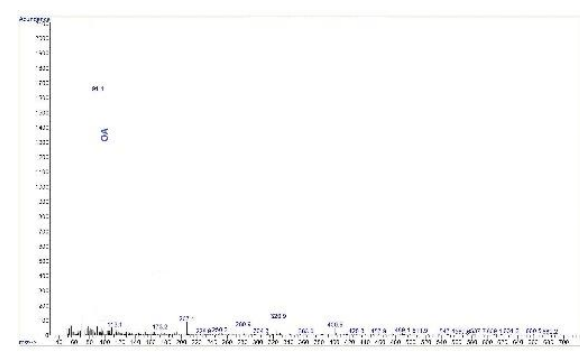

Figure 7c. Mass Spectra of OA

\section{$3.6 \%$ Conversion and selectivity}

Using $10 \% \operatorname{CBP}(\mathrm{w} / \mathrm{v})$, ozone aeration experiments were carried under uncatalysed and catalysed conditins (with three different loadings of catalysts) and under three $\mathrm{pH}$ conditions, 3, 7 and 11 . Uncatalysed studies reveal that an increase in $\mathrm{pH}$ enhances the \% conversion (Figure 8a), which proposes that ${ }^{\circ} \mathrm{OH}$ is reactive species driving the oxidation of CBP. A perusal of \% conversion data for catalyzed reactions (Figure 8b) indicates that while the catalyzed reactions are invariably faster, similar to the uncatalysed reaction the increase in $\mathrm{pH}$ enhanced the \% conversions, suggesting alkaline $\mathrm{pH} 11$ is optimum conditions for all the reactions. An examination of the \% conversion profiles in Fig. $4 \mathrm{~b}$ explicit that the composite material with $5 \% \mathrm{Ce}-\mathrm{Zr} / \mathrm{TiO}_{2}$ as catalyst gave $100 \%$ conversion in $4 \mathrm{~h}$ of ozonation, whereas the 1 and $2.5 \% \mathrm{Ce}-\mathrm{Zr}$ doped titania catalyst took $5 \mathrm{~h}$ to achieve the $100 \%$ conversion. The Figure $9 \mathrm{a}-\mathrm{c}$ also summarises the trends in $\%$ conversion of $\mathrm{CBP}$ with different wt\% of $\mathrm{Ce}-\mathrm{Zr}$ on titania at $\mathrm{pH} 11$ together with the product selectivity. The current results suggest that mixed metal loaded on support catalysts yielded good catalytic activity facilitating the ozone decomposition and enhancing the substrate conversions.

\subsection{Reaction mechanism}

The process of heterogeneous catalysis is influenced by the catalyst surface properties, target contaminants and $\mathrm{pH}$ of the solution. As a result, the establishment of formation of reactive species becomes more difficult. In the catalysed reaction, the surface Lewis acid sites especially play a vital role (Maddila et al., 2014). It is proposed that active sites on the surface of the catalyst enable the substrate binding, probably on the ceria site and the decomposed ozone attacks the organic molecule from its adjacent site. The active adsorptive sites, in addition to binding of organic molecules, also could facilitate 
the formation of activated complexes with other reactive molecules/oxy radicals minimizing the activation energy for the reaction. Adsorption of the substrate on the catalyst surface may consequently generate a five or six-membered chelate ring appears to be anionic. Overall, this will improve the oxidative dehalogenation and degradation process of the organic molecules. The reaction intermediates on the catalyst surface or desorbed into solution can easily be attacked by $\mathrm{O}_{3}$ or ${ }^{\bullet} \mathrm{OH}$ like species, generating secondary and tertiary oxidation products (Jonnalagadda et al., 2012; Maddila et al., 2013). Finally, oxidation by-products are formed due to the oxidation of surface complex by $\mathrm{O}_{3}$ or ${ }^{\bullet} \mathrm{OH}$ on surface of the catalyst by either desorption or adsorption. Essentially in this mechanism, the acidic nature of the metal contained catalysts, together with organics forms the chelate which can be further oxidised by $\mathrm{O}_{3}$ or ${ }^{\circ} \mathrm{OH}$. Thus, the proposed mechanism describes the good adsorptive properties and advantages of presence of ideal catalyst in an ozonation process.
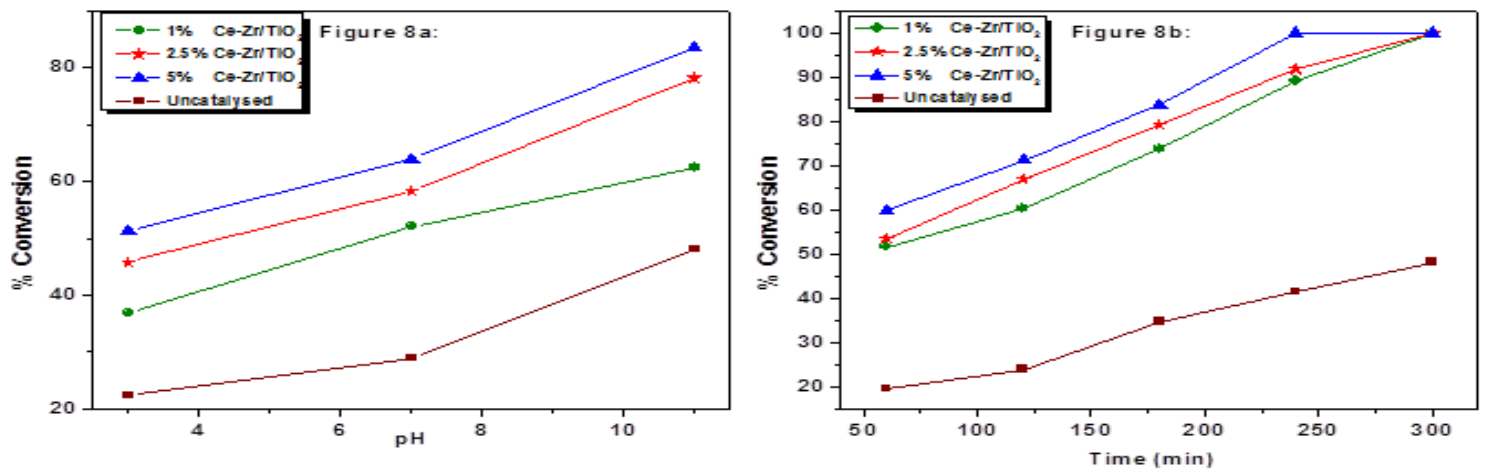

Figure 8. (a) \%Conversion of CBP ozonation with different $\mathrm{pH}$, (b) \%Conversion of CBP with time (min)
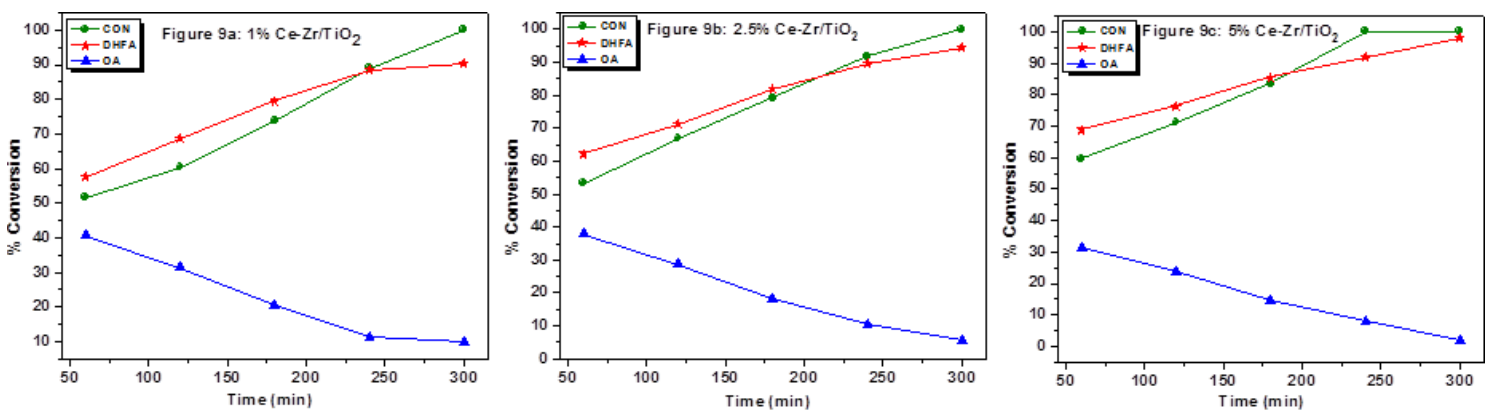

Figure 9 (a-c). The conversion and selectivity with $1 \%, 2.5 \%$ and $5 \%$ loadings of $\mathrm{Ce}-\mathrm{Zr}$ on $\mathrm{TiO}_{2}$

Ernst et al., have observed that, the organic molecule's adsorption on the surface of catalyst may not be essential to afford the catalytic effect. Besides, the adsorption would possibly hinder the activity caused by shrouding of the $\mathrm{OH}$ species (Jonnalagadda et al., 2012). In ozonation process, the $\mathrm{O}_{3}$ is initially adsorbed on the surface of the catalyst and subsequently decomposed rapidly due to the existence of $\mathrm{OH}$ species. Upon ozone decomposition, active oxygen is formed and it then reacts with support's hydroxyl surface groups to produce highly negative ions $\left(\mathrm{OH}^{-}\right.$or $\left.\mathrm{O}_{2} \mathrm{H}^{-}\right)$which in turn react rapidly with another $\mathrm{O}_{3}$ molecule to form radicals $\left({ }^{\circ} \mathrm{OH}\right.$ or $\left.{ }^{\circ} \mathrm{O}_{2} \mathrm{H}\right)$. These formed radicals further react with a new ozone molecule to produce a $\mathrm{O}_{3}{ }^{-}$. This radical is decomposed into $\mathrm{O}_{2}$, a free $\mathrm{OH}$ which can play a part in organic compound's oxidization either in solution or on the surface of catalyst. In consequence, the characteristics of organic substrate play a crucial role in its oxidative degradation during the ozone facilitated oxidations in presence of catalyst. The $\mathrm{pH}$ of solution influences the binding and desorption of organic molecules on the catalyst surface. For the many interfacial reactions, adsorption is known to be the rate limiting step, which dictates the overall removal or degradation of the organics or pollutants. The catalyst activity for accelerated generation of ${ }^{\circ} \mathrm{OH}$ radicals, is linked with the metal oxide's surface properties. Different reaction intermediates and products could possibly form during ozonation of chlorophenols. During the 
ozone initiated oxidation of chlorophenols, dechlorination and formation carboxylic acids and other hydroxylation products has been reported (Jonnalagadda et al., 2012; Chetty et al., 2012; Maddila et al., 2013). From the current study, based on the reaction products, an electrophilic attack the aromatic ring by hydroxyl radical and other species is proposed. The carbon-carbon double bonds of the oxidation products formed as a result of breaking of the aromatic ring get further attacked by ozone and hydroxyl radicals (Proposed mechanism).

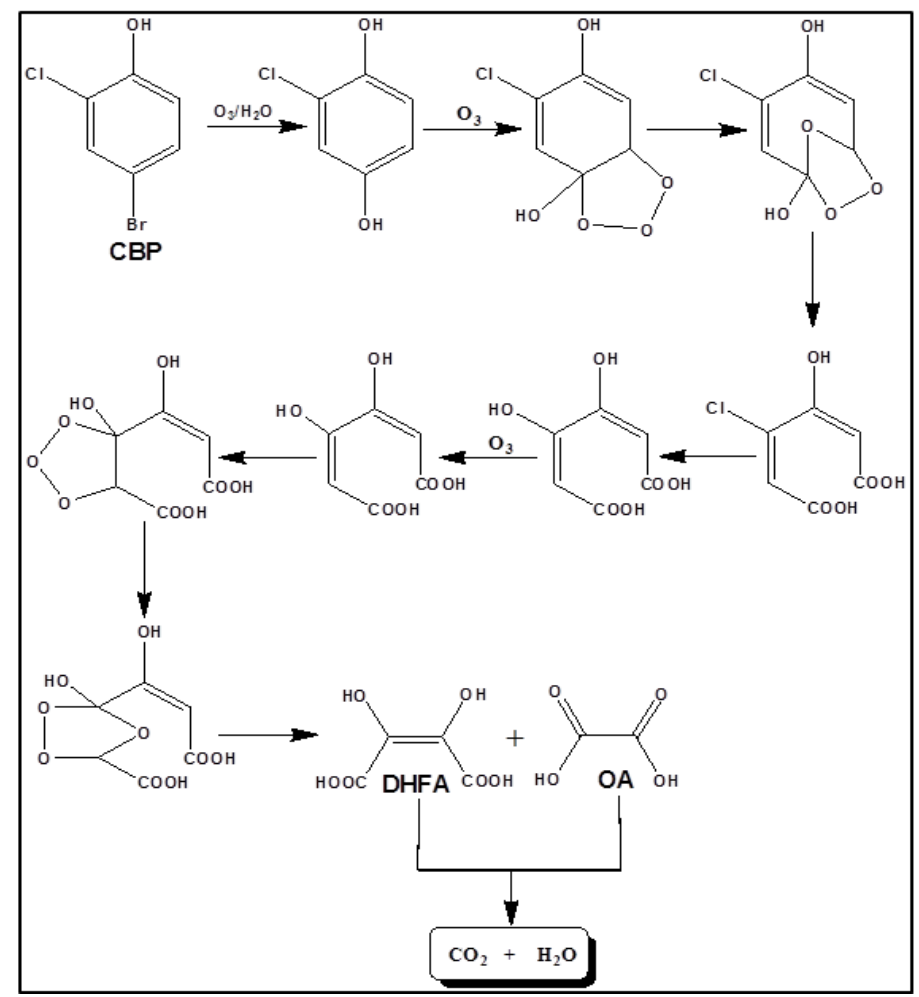

Proposed Mechanism: Mechanism of the Scheme

As reported in the literature aliphatic acids were anticipated and were found as reaction products. The prolonged reaction leads to mineralized products. Gratifyingly, the heterogeneous $\mathrm{Ce}-\mathrm{Zr} / \mathrm{TiO}{ }_{2}$ could be recovered effectively from the reaction mixture by simple filtration and by washing the catalyst twice with acetone and dried at $70-80^{\circ} \mathrm{C}$ under reduced pressure for $2 \mathrm{~h}$ to make it ready for a later run. There is no loss of Ce-Zr loading on titania was observed which is confirmed by ICP-OES analysis. The catalyst was tested for next runs.

\section{Conclusions}

Our study showed that the wet impregnation method permits the synthesis of bi-metallic catalysts with good metal dispersion. The size of catalyst particles, and reaction parameters play a significant role in ozonolysis, so catalytic properties are strongly affected by the preparation method of the catalyst. Titania is a suitable support for loading the bimetallic Ce-Zr oxide catalysts. The CBP oxidation was quantitative with $100 \%$ dechlorination. HFA and OA were main products of which OA was the secondary product, with partial mineralization. Catalysed ozonation is proved to be an effective method to remove chloro, bromo and hydroxy groups from substituted organic molecules.

\section{Acknowledgements}

This work was financially supported by the National Research Foundation, South Africa and research facilities were provided by University of KwaZulu-Natal, Durban, South Africa. 


\section{References}

Chetty E.C., Maddila S., Dasireddy V.D.B.C. and Jonnalagadda S.B. (2012), Efficient conversion of 1, 2dichlorobenzene to mucochloric acid with ozonation catalyzed by $\mathrm{V}_{2} \mathrm{O}_{5}$ loaded metal oxides, Appl. Catal. B: Environ., 117-118, 18-28.

Jonnalagadda S.B., Pullabhotla V.S.S.R., Maddila S. and Chetty E.C. (2012), Ozone for drinking and wastewater treatment and for value added products, Int. J. Chem. 1(1), 119-129.

Kasprzyk-Hordern B., Ziolek M. and Nawrocki J. (2003), Catalytic ozonation and methods of enhancing molecular ozone reactions in water treatment, Appl. Catal B: Environ., 46, 639-669.

Maddila S., Dasireddy V.D.B.C. and Jonnalagadda S.B. (2013a), Ozone initiated dechlorination and degradation of trichlorophenolusing Ce-Zr loaded metal oxides as catalysts, Appl. Catal. B: Environ., 138-139, 149-160.

Maddila S., Dasireddy V.D.B.C. and Jonnalagadda S.B. (2013b). Dechlorination of tetrachloro-o-benzoquinone by ozonation catalysed by cesium loaded metal oxides, Appl. Catal. B: Environ., 138-139, 149-160.

Maddila S., Dasireddy V.D.B.C. and Jonnalagadda S.B. (2014). Ce-V loaded metal oxides as catalysts for dechlorination of chloronitrophenol by ozone, Appl. Catal. B: Environ., 150-151, 305-314.

Maddila S., Oseghe E.O. and Jonnalagadda S.B. (2016a), Photocatalyzed ozonation by Ce doped $\mathrm{TiO}_{2}$ catalyst degradation of pesticide Dicamba in water, J. Chem. Tech. \& Biotech., 91, 385-393.

Maddila S., Palakondu L. and Jonnalagadda S.B. (2015b), Degradation, mineralization of bromoxynil pesticide by heterogeneous photocatalytic ozonation, J. Indu. \& Eng. Chem. 24, 334-341.

Maddila S., Rana S., Maddila S.N., Chandrasekhar V. and Jonnalagadda S.B. (2015a), Ozone driven photocatalyzed degradation and mineralization of pesticide, Triclopyr by Au/TiO 2 , J. Environ. Sci. \& Heal. Part B, 50, 1-13.

Oseghe E.O., Ndungu P.G. and Jonnalagadda S.B. (2015), Synthesis of mesoporous $\mathrm{Mn} / \mathrm{TiO}_{2}$ nanocomposites and investigating the photocatalytic properties in aqueous systems, Environ Sci Pollut Res Int., 22(1), 211-222.

Reddy B.M., Khan A., Yamada Y., Kobayashi Y., Loridant S., and Volta J.C. (2003), Raman and X-ray photoelectron spectroscopy study of $\mathrm{CeO}_{2}-\mathrm{ZrO}_{2}$ and $\mathrm{V}_{2} \mathrm{O}_{5} / \mathrm{CeO}_{2}-\mathrm{ZrO}_{2}$ catalysts, Langmuir, 19, 3025-3031.

Richardson S.D. and Ternes T.A. (2014), Water analysis: emerging contaminants and current issues, Analytical Chemistry, 86, 2813-2848.

Slack R.J., Gronow J.R. and Voulvoulis N. (2005), Household hazardous waste in municipal landfills: contaminants in leachate, Science of the Total Environment, 337, 119-137.

Tamer E., Hamid Z., Aly A.M., Ossama El.T., Bo M. and Benoit G. (2006), Sequential UV-biological degradation of chlorophenols, Chemosphere. 63, 277-284.

Valand J., Maddila S., Friedrich H.B. and Jonnalagadda S.B. (2016b), Heterogeneous catalysed ozonation using Cu$\mathrm{Ni}$-Co oxides for degradation of dichlorophenol, Ozone: Sci. \& Eng., 38(1), 14-24.

Verschueren K. (1983). Handbook of Environmental Data on Organic Chemicals. Van Nostrand Reinhold, New York.

Zhanga Z., Cissokoa N., Woa J. and Xua X. (2009), Factors influencing the dechlorination of 2,4-dichlorophenol by NiFe nanoparticles in the presence of humic acid, J Hazd Mat., 165, 78-86. 